\title{
On Faith or Belief
}

\author{
Weicheng Cui ${ }^{1,2 *}$ \\ ${ }^{1}$ School of Engineering, Westlake University, China \\ ${ }^{2}$ Shanghai Engineering Research Center of Hadal Science and Technology, Shanghai Ocean University, China
}

Submission: September 17, 2019; Published: September 30, 2019

"Corresponding author: Weicheng Cui, Chair professor at Westlake University, China and adjunct professor at Shanghai Ocean University, China

\begin{abstract}
Nowadays the opinion of philosophy being useless seems to be very popular in young generation and they will answer you that they do not have a faith if they are asked. As far as the present author is concerned, this view is very incorrect. The power that faith brings to him is enormous. In this paper, the various issues related to faith are discussed. The main points of the paper are: (1) Faith is the same as the body, and everyone has it. The only difference is whether you believe in yourself or others. (2) Since the Hierarch has passed the historical test to be a successful person and he is more reliable to be trusted than yourself. (3) There are three criteria to consider when choosing the Hierarch. The first is whether the life of the Hierarch is what you need; the second is whether the theory of the Hierarch can stand the test of scientific standards; the third is how many great people were cultivated by this philosophy. (4) Five suggestions on how to apply faith to guide your work or life are given. (5) Finally, the author proposed a nine-floor life model that is constantly improving yourself and Hawkins' levels of consciousness measurement can be used to detect the floor you have reached.
\end{abstract}

Keywords: Universe; Life; The Buddhist cosmological model (BCM); Philosophy; Faith; Belief

\section{Introduction}

At the celebration of the 40th anniversary of China's reform and opening in December 18, 2018, President Xi Jinping said, "Faith, conviction, and confidence are vital at all times. Small to one person, one collective, big to a political party, a nation, a country, as long as there is faith, conviction, confidence, it will become more and more courageous and brave, otherwise it will be defeated and self-destructed" [1]. But when I asked the graduate students who came to me for an interview the question what your faith or belief is, most people usually answered me that "I don't have a faith". Faith and conviction are the contents taught in the philosophy curriculum. From this phenomenon, at least two problems can be revealed. First, the philosophy taught at school and university was not accepted by them and did not become their faith or belief. Second, they might think that philosophy is useless, so they had not tried to find another philosophy for them to believe in. For them, they may believe that only scientific and technical knowledge and the ability to solve practical problems are important. Philosophy is useless. Whether having a faith or not does not matter. As far as my personal experience of scientific research and daily life for more than 30 years is concerned, this view is incorrect. The power that a faith brings to me is enormous. Therefore, in this paper I would like to present my views on various issues related to faith or belief.

\section{The Functions of Faith/Belief}

According to textual research, the two Chinese characters as a Chinese word first appeared in the Buddhist translation of the "Mahavaipulya Buddhavatamsaka Sutra" translated by Siksananda at The Tang Dynasty [2]. All the immortals are superior, people and others have similar beliefs. If it is difficult to practice asceticism, the Bodhisattva should be able to. In Buddhism, faith was focused on the Triple Gem, that is, Gautama Buddha, his teaching (the Dhamma), and the community of spiritually developed followers, or the monastic community seeking enlightenment (the Sangha). Later, the meaning of the word "faith or belief" changed slightly and could be used to express respect for a certain philosophy, religion, someone, something, and to the beliefs of heaven and earth, God, gods and ancestors. Therefore, the Chinese word faith or belief has a history of at least 1300 years of use. For this Chinese word, we can also understand the two characters like this: trust in self or others is a way of life, and "admire others" is a pursuit of life. The English word "Faith", derived from Latin fides and old French feid, is confidence or trust in a person, thing, or concept. In the context of religion, one can define faith as confidence or trust in a system of religious belief. Religious people often think of faith as confidence based on a perceived degree of warrant, while 
others who are more skeptical of religion tend to think of faith as simply belief without evidence [3]. From this author's point of view, people can only believe in something that he/she cannot falsify it although the ability to falsify a statement is different for different people or even different at different time for the same person. It is hard to judge that someone believes in something without evidence. Therefore, in this paper faith and belief are used interchangeably.

Faith is the subjective product of the mind and the individual's conscious behavior [3], but the education from the family and society has a major impact on the individual's beliefs. Joining an organization (such as a religion community, a political party, and other organizations) is not only a sign of personal belief, but it also has the potential to influence the substantive content of personal beliefs. However, some people may join a certain organization for personal gain. They do not care about the pursuit of the organization. This belief is a false belief, and it will disappear with the disintegration of the organization. Human beliefs include primitive beliefs, religious beliefs, philosophical beliefs, etc. Faith is a spiritual sustenance, which has three effects on individuals:

a) Faith not only gives morality of the self-discipline nature and meaning, but also the coordinates of people's spiritual pillars and moral choices.

b) Faith can not only improve people's moral realm, but also shape people's moral personality.

c) Faith is not only the driving force of moral behavior, but also the "pointing light" on the road of life.

\section{How to Select a Faith}

\section{In fact, everyone has faith}

As we know, trusting in self or others is a way of life and this trust is just the faith. Since everyone must live, everyone has faith which is the same as he has his own body. Saying that he has no faith, just like saying that he has no body, is inaccurate. People face choices every day in their lives. Should I do or not do something, even if I choose to do it, what attitude should I do it? These questions are about values, outlook on life, and worldview, all of which are answered in the belief system. Beliefs are all about ethical standards. Different beliefs represent that they accept different levels of social ethics. At present, the content of faith in the society is varied widely [3]. Harmony between man and nature, God's faith, Buddha's faith, scientific belief, obsession and worship of power, status, money, reputation, beauty, etc., "timely fun", "do one day monk knocking one day", "Muddle along" are all different kinds of beliefs.

\section{Believe in yourself or others}

Life is like walking, and you will continue to encounter intersections. At this point, you will face the choice of left, right or straight ahead. How to choose depends on how clear your destination is. If you do not have faith, you do not know the final goal of your life. There are two ways to make decisions at this point. One is to believe in their own instincts, and the other is to rely on the guidance of others. People always want to reach their destination with the least effort and the fastest speed. But since they have not walked before, how can they guarantee that they can obtain the best solution with their own instincts? Most people think that they will not harm themselves, and others may deceive them. However, many examples can be found around us that someone made the wrong choice because of his ignorance. Because I am only the individual person, while others have many and they also include those successful persons in history. Therefore, one of my conclusions is that it is much more reliable to choose historically proven characters such as Sakyamuni (563-480 BC), Jesus (4 BC30 AD), Confucius (551-479 BC), Laozi (571-471 BC), Newton (25 December 1642- 20 March 1726/27), Einstein (14 March 187918 April 1955), etc. than to choose himself because they have already succeeded. Choosing the majority of people around you does not seem to be risky at the first sight, but it also determines that you can only be an ordinary person and cannot reach the high level of life since they are not historically proven to be successful persons.

\section{How to choose a credible person}

\section{Is his life what I want?}

It is said in "The Mahayana is away from the text of the Puguang Ming Scriptures", "No beings love pain, and all their desires are happiness" [4]. But in real life, we will see that most people still live in pain and upset, and often see news such as "Someone suddenly commits suicide" and "a major killing occurred somewhere". All these suicides or murderers must have reached the point of his pain before making such a choice. Why do they have problems and cannot find a better solution? I think an important reason is that they do not believe in others, and they cannot provide better solutions for themselves. Therefore, choosing a person as your own belief object may avoid such problems. How to choose is obviously determined by personal values, outlook on life and worldview. These are the categories of philosophy [5].

There is no absolute good or bad philosophy. There is no way to prove the truth by scientific means. Therefore, there is no standard answer, and ultimately it is the choice of belief or not. But here, I want to propose a new simple selection criterion. "The philosopher is the best practitioner of his own philosophy. Is his life that I am longing for? If yes, you can choose him as the object of faith, otherwise, you do not choose him". The present author had compared the lives of the three thinkers of Sakyamuni, Confucius and Marx [6]. For him, he feels that Sakyamuni's life is the most complete. Therefore, he chose Sakyamuni as a candidate for faith and began to study his theory in depth [7].

\section{Does his theory stand the test of scientific standards?}

The development of human civilization to modern times benefits much from the development of science. But until now, 
people still have no unified understanding of what is science and what is the standard of science/pseudoscience $[8,9]$. The present author has also made some studies on this issue $[10,11]$.

Philosophers and scientists have attempted to provide a fully fundamental definition of science, but not very successful [12]. In fact, since the term science has never been strictly defined, many of the arguments are caused by inconsistencies in concepts. Based on the analysis on the respective problems of the six existing definitions, a recommendation was given as follows [10].

"Science is a kind of knowledge system that humans use rational thinking to reveal movement and change laws that do not contain contradictions and can reflect certain phenomena in the real world. It is one of social ideologies".

For the standard of science/pseudoscience, it is well-known that Popper suggested that "anything that can be falsified is science, anything that cannot be falsified is pseudoscience" [13] while others suggested that "anything that allows others to perform repetitive verification is science and anything that does not allow others to perform repetitive verification is pseudoscience". Braude analyzed in detail the reasons why the second standard is inappropriate [9]. It is believed that in the philosophical sense, no test can be repeated, and the time of the test, the environment of the test, and the mentality of the person participating in the test can all affect the test results, and these factors are not repeatable. The so-called repeatable tests refer to tests in which these factors have little effect on the experimental results.

For the first criterion, the present author put forward his view [11] that the characteristic of science is falsification. Therefore, there is no pseudo-theory that cannot be falsified scientifically. The theory has not been falsified today does not mean that it cannot be falsified in the future. Of course, there may be cases where the error in the proving method is not recognized. The theory that has been falsified today is found at some future time that the proving method is wrong rather than the theory itself. Second, the theory that has been falsified today is not appropriate to treat it as a scientific theory anymore. Therefore, it is suggested that the boundary of science/pseudoscience should be dynamic, but the standard is certain. "Any theory that is not falsified is science". Since science cannot prove the truth, what is revealed in science is the law of the development of things rather than the truth. Treating the laws of science and even science itself as truth is a kind of faith, which itself violates the characteristics of "science can always be questioned".

Science is by far the best falsification tool that humans can rely on, but it cannot prove the truth. That is to say, the theory that cannot pass the scientific standard test is problematic, but a theory which can pass the scientific standard test today does not mean that there will be no problem in the future. What we choose now should be the theory that has not been falsified yet. To falsify a theory is to find a counterexample that violates the basic assumptions or derive a paradox based on the basic assumptions.
Based on such a criterion, the present author compared materialist philosophy with Buddhist philosophy [14-17], and argued that the Big Bang theory based on materialist philosophy has the following difficulties:

a) How are elementary particles produced? Materialistic philosophy faces the same "creator problem" as Christian philosophy [18].

b) Where does the force of elementary particle motion or particles synthesizing into a large object come from?

c) There exists logical paradox between entity particles with weight and volume and inseparable property. Yixi Pengcuo pointed out that "entity particles" can lead to ten major paradoxes about matter [19].

d) Since Einstein discovered that matter can be transformed into energy (his famous equation $\mathrm{E}=\mathrm{mc}^{2}$ ), it has been proved that the inseparable entity particle hypothesis is wrong.

e) If matter can be decomposed into energy and energy cannot be eliminated or destroyed, a natural question would be "can energy be accumulated into matter?"

In response to these problems, the present author has proposed a new cosmological model based on Buddhist philosophy (BCM) [16] and believes that BCM can withstand the test of scientific standards and can eliminate all the paradoxes of the Big-Bang Cosmological model [17].

Any scientific theory contains three elements: (1) basic assumptions (axioms); (2) theorems; (3) phenomena. The theorems can be derived from the logical deduction from the axioms or from the logical induction from the natural phenomena. Based on theorems, people can explain the phenomenon that has occurred or predict the phenomena that may occur in the future.

If the basic assumptions are based on unfalsifiable statements, the philosophical foundation of the theory is consolidated. Adopting such assumptions is the same as how to deal with the philosophical "singularity". The concept of a singularity comes from mathematics. "There is a point in the universe, in which the treatment itself fails." This is an example of what mathematicians call singularity [20]. According to the current scientifically popular Big Bang theory, the whole Universe came from a singularity. BCM does not adopt this assumption.

The philosophers have an uncontrollable desire to seek an "absoluteness". This absoluteness is unconditional to any precondition or condition of any other thing, but also a precondition and condition for all things and itself. It is also the first cause, the self-cause and the ultimate cause. Whether we call it absolute, existence itself, entity, self-cause, first cause, pure consciousness, absolute spirit, transcendental self, or life impulse, free will, ontology, object self, pure experience, "thing itself", God, or anything else, the premise of pursuing the ultimate "no precondition" of the "foothold" and "starting point" is the 
same thing with different names. The last thing, we can also call it a philosophical "singularity" [21], at which point the theory itself is virtually ineffective. The reason why there is no such a metaphysical theory is that people always try to maintain the validity of the theory itself at the singularity, which is precisely the contradiction with the singularity. It may be the root of all scientific paradoxes [22].

For modern science, there are still many problems that are not recognized, such as whether the Universe is finite or infinite, whether the Universe is running regularly or randomly. If the Universe is running regularly, are the laws governing the operation of the Universe cognizable or not? What is dark matter and dark energy? What is human consciousness? What is the essence of life, where do we come from, where do we go after death, who am I? Is there a fundamental difference between artificial intelligence and human intelligence, and will artificial intelligence surpass human intelligence? These issues have been selected as the most cuttingedge scientific issues by Science magazine in 2005 [23].

Buddhist philosophy has clearer answers to these questions. First, by distinguishing the concepts of the Universe and the world, Buddhism defines the Universe to be of infinite nature both in space and time and the world to be of finite nature both in space and time. In space, the Universe consists of an infinite number of worlds. In time, each world is cyclically operated according to the process of formation, the steady state, deterioration and explosion to emptiness. In BCM, the Big Bang is the origin of the world but not the Universe. Using this definition, the awkward question of the origin of the Universe can be avoided. Because the Universe is infinite, it is unknowable. The operation of each world is regular. This law is collectively called the law of causality and can be known. However, for large and complex world problems, because of the limited life span of human beings, there are many influencing factors that may not be recognized yet. Therefore, there will always be uncertainty. In this case, the use of probability and statistics theory can give a better forecast of statistical laws, but it does not prevent a small group of people from continuing to explore the mechanism and find out more influencing factors (hidden variables). Therefore, the dispute between Einstein and Bohr is completely reconcilable [24,25].

The range that human beings can observe, no matter how big it is, is essentially a world. The space-time scope referred to by the current big bang theory is the world we live in, and it is still in a state of expansion in space. If it is the whole Universe, there is a spatial paradox between the whole Universe and the Universe expanding. Since the world we can observe and the other worlds always have the exchange of matter, energy and information on the boundary, the world is an open system, and any theorem derived from the use of isolated or closed hypotheses is inherently of applicable range [26].

Materialism describes the essence of the world as matter of fundamental particles, and the fundamental particles are inseparable into smaller particles. This assumption cannot answer the question of how fundamental particles are produced, and there are logical paradoxes between the entity particles of weight and volume and the inseparable property. The Buddhismbased Universe model (BCM) describes the essence of the world as energy. There are two kinds of energy, material energy (as the common term of energy we used and hereafter we just call it energy) and life energy (which may correspond to the dark energy we are looking for and hereafter we will call it mind). As is well-known that energy cannot be destroyed and satisfy the law of conservation. However, mind and energy are two independent forms of basic energy types. They cannot be transformed into each other. But mind could accumulate energy into matter or decompose matter into energy. Mind itself is also a kind of life.

The combination of mind and a body can constitute our countable life. For the life we can count, mind is equivalent to the engine that drives the body's movements, and it is also the engine that drives the various organs of the body to perceive the external world. This ability is known as consciousness. Human's consciousness includes 8 types, they are consciousness at eyes, ears, nose, tongue, body and brain, the manas consciousness, and finally the alaya consciousness. Mind is the alaya consciousness. When one is dying, the consciousness at eyes, ears, nose, tongue, body and brain willbelost. Thefunction of theseventh consciousness whose formal name is called the manas consciousness, is the bridge between the former six consciousnesses with mind. Only mind will continue to exist, and it is the source of life forces and it stores all the karmas in the previous life history. The dying process is a process of the separation of mind from the body. For the detailed theory of Buddhism, one can refer to reference [7].

The matter accumulated by mind can be classified into visible matter that can be perceived by our humans and dark matter that cannot be perceived at present. Obviously, the boundary between visible and dark matter is also dynamic. As our ability of perceiving the matter (including the self-perception ability obtained through meditation and the external perception ability obtained through the development of advanced instruments) improves, more dark matter becomes visible matter. The body of a life also has two categories of matter and dark matter. The former is like humans and animals, and the latter is like Heaven, Asura, Ghost, Hell. The highest speed at which matter, and energy can be transmitted is the speed of light, and the speed at which mind can be transmitted through the entanglement mechanism can exceed the speed of light. Inanimate matter has a local limitation, that is, various characteristics gradually decay as the distance becomes longer; while mind is always global, and its related properties do not decay with increasing distance. But if mind is combined with the body, for those characteristics appeared through the body, they also have attenuation property, such as human vision and hearing.

These are the main points in the BCM model. The present author believes that BCM can pass the test of scientific standards 
and can overcome the various problems existed in the current Big Bang cosmological model (BBCM) and pointed out the direction for the future development of sciences $[11,16,17,26]$.

Are there persons who are worth admiring among the believers of the theory?

For the second scientific standard test, the believer must be able to do it after he has a high level of scientific knowledge. The ordinary persons may not have this ability. In this case, there is a simpler criterion to look at history. Check that since the theory was put forward, how many people believe in this theory, and among the believers, how many people are worthy of admiration? If this philosophy has not cultivated the characters that you can admire for quite a long time, it means that this theory is not suitable for you. Maybe there are still some problems in this theory, although you do not have the ability to prove it theoretically. For example, materialist beliefs and Buddhist beliefs have a history of more than 3,000 years. Among the materialist believers, I have not found any character whose moral realm I would like to admire, and the masters of Buddhism that I admire are many, such as Sakyamuni (563-480 BC), Ashvaghosha (80-150 AD), Nagarjuna (150 - 250 AD), Xuanzang (April 6, 602-March 7, 664), Hui Neng (638-713), Xu Yun (September 5,1840-October 13,1959), Yin Guang (January 11, 1862-December 2,1940), Hong Yi (October 23, 1880-October 13,1942).

This is an important reason why I personally turned from materialist belief to Buddhist belief. When I was in college, I learned Master Hongyi and chose him as my idol of life. I began to study the life of Sakyamuni and his Buddhist philosophy by studying why Hongyi believed in Buddhism, and then used the scientific standards I learned to test Buddhism. It was found that it does not conflict with science, and in many cases, it can provide solutions to phenomena that cannot be explained by modern sciences or solve paradoxes in modern sciences. This is the complete course of the birth of BCM.

\section{Practice of Faith/Belief}

\section{Read the biography of the Hierarch carefully and understand his way of thinking}

The general process of seeking a faith may begin with idols. First, you study the biography of idols, understand the way of thinking of idols, and then explore what the idols believe, and then study the biography of the Hierarch and the theory of philosophy or religion proposed by the Hierarch and his followers. Religion is basically a philosophy plus science and the way to learn or practice this religion. In the beginning, you can focus on the philosophical and scientific aspects to see if this philosophy and science can pass the test of scientific standards. If it fails, this philosophy and science are not what I ultimately want. If it can pass the test, I can also choose this philosophy as the basis of my faith. In-depth study of the way the Hierarch and the idols think and then use their ways of thinking to deal with all the problems you encountered in your work and life.

\section{Seriously study this philosophical theory and understand the general method of solving problems}

As we have understood that this philosophical theory is not in conflict with science, and philosophy is the foundation of science, we will further study this philosophical theory and understand the general method of this philosophy to solve problems. For example, Sakyamuni saw both the poor and the rich were living in pain and trouble, he was willing to find a way to solve all human sufferings and troubles. By learning from existing knowledge, no solution was found; by learning from other masters, it was found that their methods are not thorough to solve these problems; finally, through his own meditation, he claimed to have found a general way to solve the painful troubles. The main points of this theory can be summarized in the following four aspects:

a) All the painful troubles are not caused by others and the environment, but the way you see the world is not right (Ignorance);

b) Why is it wrong for me to see the world? Because I divide the whole world into two parts, belonging to me and not-belonging to me, and then try very hard to make the notbelonging to me to become the belonging to me. If I cannot change it, I will feel pain and upset (self-attachment);

c) Therefore, to eliminate the pain and worry, I must change my way of looking at the world. I must understand that the world is operating according to the law of causality (eliminating ignorance);

d) In order to truly eliminate the ignorance, I must eliminate self-attachment. I should expand my mind and let myself be equivalent to the world. I am the world; the world is me. Any life in the world is a cell in my body, and only if they have a good life, can I really live well. Sakyamuni has taught many different methods of practice to different people based on their actual levels. I personally think that this theory is very logical, and many people in history have practiced according to this theory, and truly achieved the degree of relief of pain and trouble. I have practiced this theory for more than 20 years and I feel that the effect is very good.

\section{Apply the theory to your work and life}

Since you believe in a philosophical theory, you can only appreciate it if you apply it to your work and life. Just like a person getting sick, he got a good medicine from a doctor. Only when he took the medicine can he see the effect. If he does not take the medicine, it would be useless for him to have a good medicine.

Since I know from Buddhism that there is no difference between putting wealth in my home and putting it in someone else's home, I do not have to earn the extra wealth that I do not need. I only need to keep my own or my family's need for living. Now, I can put more energy into my research. I can use my unnecessary wealth to help others. In this way, my relationship with my family and friends will be very harmonious. I will live in 
a happy environment. If I use this kind of thinking, I can always build a harmonious environment around me. Let me focus more on my work. I could do my job better, the more I will be paid by the society. The more I use the extra saving to help people, and the bigger is my harmonious environment.

If you understand that the essence of life is mind, the mind is not inexhaustible, the death of the body is like changing a piece of clothing, and through my good deeds, my next life is better than this life. Then I lifted my fear of death. Once someone has not been afraid of death, there is nothing else that can make him fear again if he is living on earth. As the "Heart Sutra" said, "Since there is nothing to attain, the bodhisattva who accords with the perfection of wisdom has no mental impediments. Because there are no impediments, there is nothing to fear. The departure from inverted and illusory ideas is ultimately Nirvana" [27].

\section{In case of major problems, it is necessary to try to figure out how the Hierarch will solve this problem}

The question of faith is essentially the question of believing in yourself or the Hierarch. For many things in daily life, the judgment by your instinct and the judgment of the doctrine may be the same, but for some major or complicated problems, more should be to give up your instinctive judgment and turn to the help of the Hierarch. Therefore, the first thing to do is to regard yourself as the Hierarch, to figure out what he will do when he encounters this

\section{A Constantly Improving Life Model}

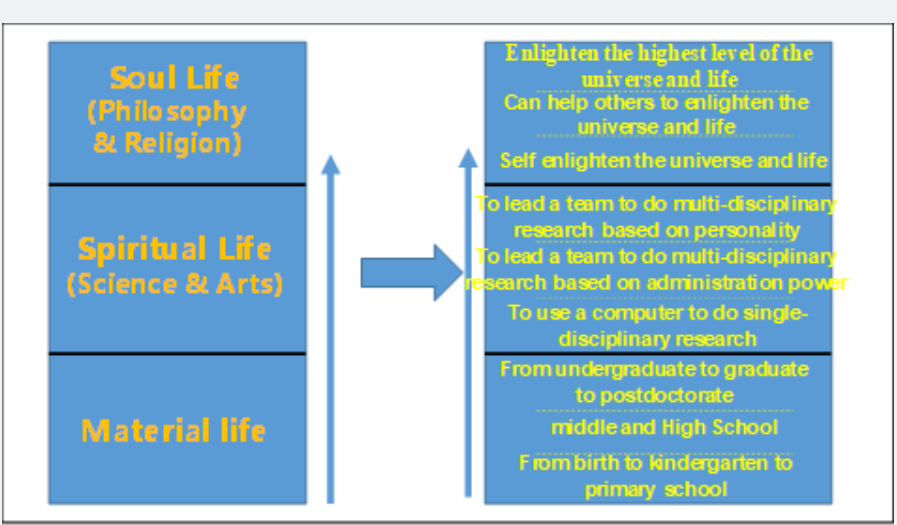

Figure 1: Feng Zikai's three-storey life model (left) and Cui Weicheng's nine-floor life model (right).

Feng Zikai proposed a three-storey life model in interpreting Hongyi's lifestyle. The first floor is a material life manifested by money, the second floor is a spiritual life manifested by science and art, and the third floor is a soul life manifested by philosophy and religion, shown in (Figure 1) [28]. The present author has refined this model into a nine-floor model that is practical and measurable, shown in (Figure 1). The first floor is from birth to primary school, the second floor is the middle school, and the third floor is the university stage, from undergraduate to postdoctorate. If your ability is strong, you may be able to solve your own survival problems at this stage, then you can concentrate on problem. It would be much reliable to solve the problem according to such a way of thinking rather than relying solely on your own instinct to judge, because the Hierarch has become an immortal success in history with his unique way of thinking.

\section{I feel that the Hierarch is watching me all the time and I dare not do bad things. Once I have a bad idea, I must regret it immediately}

For those who have faith, a very effective way to improve your moral realm is to let yourselves live under the camera. You believe that the Hierarch is watching you all the time, so you do not dare to do bad things. And his surveillance ability is much stronger than the camera, not only he can record your words and deeds, but also your thoughts. Therefore, you should rush to repent if you have bad thoughts. Over the time, you will dare not have any bad thoughts, so you become a very fulfilling person. Your life will continue to be perfect, which has nothing to do with the specific occupation. Those who are engaged in any profession, as long as they believe in the teachings of the Buddha and put into practice, rely on the constant persistence of life after life, and eventually they can become Buddha. A fundamental difference between Buddhism and theology is that everyone has buddha nature and everyone can become a Buddha. The Buddha is a person who has realized the laws governing the life and the Universe, not the savior who created everything in the Universe and determined the fate of every life. scientific research or artistic creation afterwards. If your academic level is high and your achievements are rich, the salary paid by the society is relatively high. You can continue a good material life while pursue a spiritual life of higher levels.

Taking scientific research as an example, there can be a triple realm for this career from fourth floor to sixth floor. The fourth floor is that you can direct yourself and the computer to solve a singledisciplinary problem. The fifth floor is the use of administrative power to direct a team to conduct multidisciplinary research, and to develop a product with practical value in the future. However, 
because the resources of administrative posts are very limited, not everyone can have the chance to be promoted. Some highly capable people do not necessarily have this opportunity. Those who have such an opportunity can continue to climb. The sixth floor relies on one's personality charm to direct a team to conduct multidisciplinary research. However, people should constantly think about such problems in the process of scientific research. Why should I do scientific research? What good is it for my life? What is the standard of success for my life? After thinking about these questions, it can be said that you are starting to climb the seventh floor of Self enlightening the Universe and life. If you can help others to enlighten the Universe and life, you are judged to reach the eighth floor. We define the Buddha who has enlightened the highest realm of the Universe and life as the ninth floor. This is a nine-floor life model from how an ordinary person can improve his moral realm step by step.
Whether it is possible to establish a measurement method for the moral realm of self-cultivation in the process of becoming a Buddha, let yourself better understand the degree of selfcultivation and build confidence in cultivation. We found that Hawkins' levels of consciousness theory [28] can fully match this nine-floor life model, shown in (Figure 2). Based on the present author's understanding of Hawkins' levels of consciousness theory, it is suggested that level 4 corresponds to 150-200, level 5 corresponds to 200-250, level 6 corresponds to 250-350, level 7 corresponds to 350-500, level 8 corresponds to 500-700 and level 9 corresponds to 700-1000. Persons in the first three floors are defined according to the age and there is no specific correspondence to the levels of consciousness, most of persons may be within the range of 100 to 200 and there are some persons may exceed 200 and of course few persons may be less than 100 .
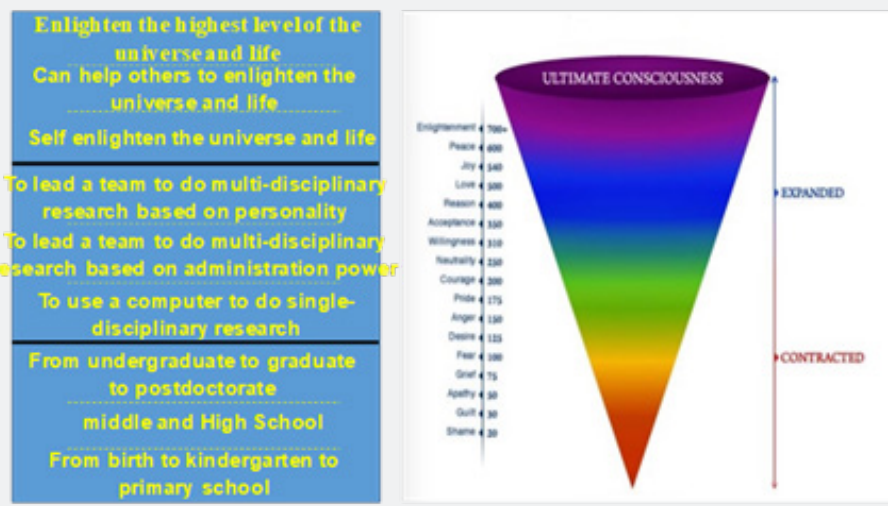

Figure 2: A simple correspondence of nine-floor life model with Hawkins' levels of consciousness theory.

\section{Summary and Conclusion}

Based on the phenomenon that most of the interviewed students answered that they do not have a faith, the various issues related to faith are discussed in this paper. It is thought that there are two main reasons for this problem. One is that the materialistic philosophy taught at school and university was not accepted by them and does not become their faith. Second, they may think that philosophy is useless, and they have not tried hard to find another philosophy that they would like to believe as the object of their faith. For them, it seems that only scientific and technical knowledge and the ability to solve practical engineering problems are important. Whether or not there is faith does not matter. As far as my personal experience in scientific research and life for more than 30 years is concerned, this view is very incorrect. The power that faith brings to me is enormous. Therefore, the author has presented some thoughts on the issues related to faith in this paper. The main points can be summarized as follows:

a) Faith is the same as the body, and everyone has it. The essential difference is whether you believe in yourself or others. The so-called people without faith means that they believe in their instincts and knowledge and do not believe in others; b) Since the Hierarch has passed the historical test to be a successful person and you have not yet walked the path of life, the Hierarch is more reliable to be trusted than yourself;

c) There are three criteria to consider when choosing the Hierarch. The first is whether the life of the Hierarch is what you want; the second is whether the theory of the Hierarch can stand the test of scientific standards; the third is how many great people who have worshipped this philosophy have cultivated.

d) Five suggestions are offered on how to apply faith to guide your work or life.

i. Carefully read the biography of the Hierarch and understand his way of thinking.

ii. Study this philosophical theory carefully and understand the general problem-solving method.

iii. Apply the theory to your work and life.

iv. When you encounter a major problem, you should try to figure out how the Hierarch will solve this problem. 
v. Always feel that the Hierarch is watching you and you dare not do bad things. Once you have a bad idea, you should regret it immediately.

e) Finally, the author proposed a nine-floor life model that is constantly improving oneself and Hawkins' levels of consciousness measurement can be used to detect the floor one has reached.

\section{Acknowledgement}

This work was supported by the State Key Program of National Natural Science of China "Structural Reliability Analysis on the Spherical Hull of Deepsea Manned Submersibles" (Grant No. 51439004), the General Program of National Natural Science of China "A study on the water absorption property of the buoyancy material for the full ocean depth manned submersible" (Grant No. 51879157), the "Construction of a Leading Innovation Team" project by the Hangzhou Municipal government, the Startup funding of New-joined PI of Westlake University with grant number (041030150118).

\section{References}

1. Xi Jinping (2018) A speech made by president Xi Jinping at the Congress Celebrating the $40^{\text {th }}$ Anniversary of China's Reform and Opening-up. China.

2. Mahavaipulya Buddhavatamsaka Sutra translated by Siksananda at The Tang Dynasty in Chinese. China.

3. https://en.wikipedia.org/wiki/Faith.

4. Mahayana Leaves the Word Puguang Tibetan Sutra translated by Di Borneo at The Tang Dynasty in Chinese. China.

5. https://en.wikipedia.org/wiki/Philosophy.

6. Cui, WC, Kang BL (2008a) A comparison of the three thinkers who have the greatest influence on Chinese thinking. Journal of Chinese Social Sciences 53: 1-6.

7. Harvey P (2013) An Introduction to Buddhism, Teachings, History and Practices. ( $2^{\text {nd }}$ edn), Cambridge University Press, Cambridge, New York, Melbourne, Madrid, Cape Town, Singapore, São Paulo, Delhi, Mexico.

8. Sheldrake R (2012) The Science Delusion-Freeing the Spirit of Enquiry. Coronet, An imprint of Hodder \& Stoughton, A Hachette UK company. UK.

9. Braude, Stephen E (2018) EDITORIAL. Journal of Scientific Exploration 32(2): 255-264.

10. Cui, WC, Kang BL (2009) Some opinions on the basic definition of the scientific development outlook. Journal of Chinese Social Sciences 5(63): 1-4.
11. Cui, W. C (2019d) Some Discussions on the Establishment of a Scientific Cosmological Model. Ann Rev Resear 5(1): 555653.

12. https://en.wikipedia.org/wiki/Science.

13. Popper, Karl (1963) Conjectures and Refutations: The Growth of Scientific Knowledge (2002 ed.). Routledge. London.

14. Cui, WC, Kang BL (2008b) Comparisons between Buddhism and Science: Taking Mechanics as an Example, Modern Academic Research 6(52): 1-6.

15. Cui, WC, Kang BL (2008c) Comparison of Buddhist Philosophy and Dialectical Materialism Philosophy. Journal of Social Sciences of China 7(54): 1-6.

16. Cui, WC (2019b) On A Logically Consistent Cosmological Model Based on Buddhist Philosophy. Ann Soc Sci Manage Stud 3(1): 555605.

17. Cui, WC (2019c) A Comparison of BCM with BBCM. Ann Soc Sci Manage Stud 3(3): 555612.

18. Sarfati JD (1998) If God Created the Universe, Then Who Created God? CEN Tech J 12(1): 20-22.

19. Yixi Pengcuo (2017) the ten paradoxes of matter. China.

20. Hawking, Stephen (1988) A brief history of time, Bantam Dell Publishing Group. China.

21. The Singularity of Philosophy, Philosophical Thought and Ideology Headline. China.

22. Clark, Michael (2007) Paradoxes from A to Z. ( $\left.2^{\text {nd }} e d n\right)$, Taylor \& Francis e-Library, China.

23. Science (2005) 125 big questions that face scientific inquiry over the next quarter-century. Science 309: 1.

24. Cui, WC, Kang BL (2008d) Examining the debate between Einstein and Bohr based on Buddhist philosophy. Journal of Chinese Social Sciences 8(55): 1-9.

25. Cui, WC (2019a) A Simple Idea on the Unification of Einstein-Bohr Controversy. Ann Soc Sci Manage Stud 2(5): 555597.

26. Cui, WC (2019e) On Conservation Laws for an Open System Based on BCM. Ann Rev Resear 5(1): 555654.

27. The Heart of the Perfection of Wisdom Sutra translated by Xuanzang at The Tang Dynasty. China.

28. Feng, Zikai (1996) I was with Master Hongyi, a speech made in Xiamen Buddhist Society on November 28, 1948, Hong Fan Publishing House. China.

29. Hawkins, David R (2014) Power vs. Force Power vs. Force: The Hidden Determinants of Human Behavior, Paperback, Published by Hay House Inc. China, p. 416. 
This work is licensed under Creative Commons Attribution 4.0 License DOI:10.19080/ASM.2019.04.555638
Your next submission with Juniper Publishers will reach you the below assets

- Quality Editorial service

- Swift Peer Review

- Reprints availability

- E-prints Service

- Manuscript Podcast for convenient understanding

- Global attainment for your research

- Manuscript accessibility in different formats

( Pdf, E-pub, Full Text, Audio)

- Unceasing customer service

Track the below URL for one-step submission https://juniperpublishers.com/online-submission.php 